\title{
The Assessment of Continuous Antenatal Care Competence in Midwifery Diploma Education: Instrument Development and Content Validation
}

\author{
Sumantri ${ }^{1{ }^{* *}, K^{\prime}}$ Kumaidi ${ }^{2}$, Lucky Herawati ${ }^{3}$ \\ ${ }^{1}$ Department of Educational Research and Evaluation, Yogyakarta State University, Indonesia \\ ${ }^{2}$ Faculty of Psychology, Muhammadiyah University of Surakarta, Indonesia \\ ${ }^{3}$ Health Polytechnic Yogyakarta, Indonesia
}

Received August 7,2019; Revised September 27, 2019; Accepted October 5, 2019

Copyright $\odot 2019$ by authors, all rights reserved. Authors agree that this article remains permanently open access under the terms of the Creative Commons Attribution License 4.0 International License

\begin{abstract}
This research aims to develop a construct of an assessment instrument of the continuous antenatal care in Midwifery Diploma Education, as well as to carry out the validity of the instrument developed. This research is a development study that adopts and modifies the procedures of Wilson Model and Oriondo Model, which consist of 3 steps that are: 1) preliminary study 2) test design; 3) trial (content validity). The construct of the continuous ANC competence assessment instrument in the Midwifery Diploma education is 18 constructs in the form of basic competence (BC). The number of question items arranged in accordance with the number of indicators in the $\mathrm{BC}$ and $\mathrm{CS}$, which were 116 items. Instrument items that had been developed were then assessed by experts using the Delphi method. The number of experts validating the contents was 21 experts, consisting of 15 experts from ANC lecturers from the Poltekkes Surakarta and Poltekkes Yogyakarta and also involving six experts from the midwife practitioners. The results of expert assessments (content validity) are then calculated using the Aiken approach. The calculation results show the average index obtained on the ANC assessment instrument of 0.830 , which means that the instrument content is declared as valid and can be used to measure ANC competence.
\end{abstract}

Keyword Midwifery Diploma Education, Continuous Antenatal Care, Competency Assessment

\section{Introduction}

Competency in medical education and assessment theory is defined as skills, the individual ability to perform skills and as an individual characteristic based on [1].
While Epstein explains competence in the clinical context is to communicate using knowledge, technical skills, clinical reasoning, emotions, values in daily practice both for personal interests and for the society [2]. In midwifery, competence is defined as a combination of cognitive, psychomotor, communication and decision-making skills which can be possible that an individual is doing a specific job to a level of proficiency (acquisition) of the job [3].

The Midwifery Diploma education program is a midwifery vocational education that is recognised by the government and professional midwifery organisations as the most basic education. The time for Education in Midwifery Diploma III is three years or six semesters with a credit load semester package (SKS) package 110-120 credits. Based on the core curriculum that has been determined the distribution of courses in the semester it can be concluded that semester I-IV is as an academic education because competence is more focused on achieving the realm of know, know-how and show how. Whereas semester V and VI are practised as professional midwifery education because competence is more focused on preparing the students to graduate to become an independent and competent midwife in accordance with midwifery competency standards or does [4].

Every university must give attention to appropriateness, in-depth and comprehensive learning to reach graduates competency level. Redfern, Norman, Calman, Watson and Murrells [5] state that clinical practice assessment is needed to ascertain whether midwifery students have the competence or not, a valid and reliable measurement instrument is needed. Evidence-Based Midwifery mentions in the UK clinical practice assessments of midwifery students make an excellent contribution for midwifery students when registering to become a midwifery 
profession. It is also said, to conduct an assessment, it needs an assessment instrument which is valid and reliable [6]. Smith [6] said that to conduct an assessment of clinical practice midwifery students must be supported by using instruments whose level of validity is guaranteed, so many methods or multi-methods are needed. Assessment of clinical practice in midwifery students has been recommended by combining NMC assessment standards made by mentors or midwifery clinical practice counsellors where checklist (yes/no) and with portfolios prepared by midwifery lecturers.

According to the search of several kinds of literature discussing clinical practice competency assessments [7-11], very few applications in midwifery and nursing education. Assessment of clinical practice is very important for midwifery students, because of health education especially midwifery, focuses on performance and proficiency, so it is necessary to develop an assessment instrument [12]. According to Robb and Dietert [13] universally, there is no valid and reliable instrument, so it still needs to be developed.

The current ANC competence assessment instrument in midwifery education is currently not receiving serious attention compared to other assessment instruments. The current ANC assessment instrument is still normative and teacher-centred in assessing ANC competency in the skills laboratory and is less comprehensive. The ANC competence assessment instrument in principle starts by first determining the basis used in the preparation of the assessment instrument. Besides, theoretical studies, studies of research results, the study of ANC programs established by the government and field studies are needed to determine the construct to be measured.

Development of a continuous ANC competence assessment instrument in a comprehensive Midwifery Diploma education is well constrained by the ability of educators, funding, and time. Besides, the availability of ANC competence assessment instruments is currently varied and comprehensive is not yet available.

Therefore, the compatible research on the development of ANC competency assessment instrument in Midwifery Diploma education is varied and comprehensive in its construction. The development of this instrument will produce an ANC competency assessment instrument as a basis for assessing and describing the ANC competence of midwifery Diploma students and the mastery of midwives' skills before getting an assignment from the health service leader.

\subsection{Purpose of the Study}

Based on the introduction, the aim of this research are:

a. Formulated the constructs and indicators used in the ANC competency assessment instrument b. To know content validity of the ANC competency assessment instrument

\section{Review on Literature}

\subsection{Antenatal Care or ANC}

Antenatal care is often called prenatal care (PNC). In the world of services for pregnant women, the term pregnancy care that is commonly used is the term ANC. Antenatal care is a treatment given to a pregnant woman during her pregnancy, with the aim of detecting, predicting, preventing and managing maternal or fetal problems and giving advice relating to pregnancy, childbirth, and newborn care. National Health and Medical Research Council (NHMRC), explains that ANC is a way of caring for women during pregnancy based on scientific evidence $[14,15]$. How to treat women during pregnancy is considered as an action based on scientific evidence which can be responsible for ensuring the safety of mothers and babies born.

Likewise, in Indonesia, the ANC is implemented through policies from the government. The form of the policy is an integrated ANC. Integrated antenatal care (ANC) is a comprehensive and quality antenatal service provided to all pregnant women and combined with other programs that require intervention during pregnancy [16]. What is meant by a comprehensive ANC is an antenatal service that includes aspects of promotive, preventive, curative and rehabilitative both the condition of the mother and the fetus. Untuk For pregnant women to receive comprehensive antenatal care, integrated programs and services in the health service unit are needed.

\subsection{Learning Continuum Approach}

The Midwifery Diploma Education Program Curriculum of 2011 states that before graduated from education students must have competencies, one of which is the ANC competency. In the curriculum, it is also said that students are declared to have ANC examination competency, must go through the stages of learning the theory and concepts of ANC in the classroom. The practice of examination procedures in the skills laboratory, the practice of examining the ANC directly in midwifery services accompanied by and the practice of examining the ANC independently and comprehensively in the service midwifery over the supervision of a supervisor or mentor.

To prepare competent and professional midwife, higher education is not only through a continuous learning process, but also because of the implementation of monitoring the achievement of learning outcomes through assessment. The learning process and ANC examination assessment of midwifery students are continuous according to the learning continuum approach. 


\section{Research Methods}

\subsection{Development Model}

ANC competence assessment instruments developed in the form of non-tests, in the form of performance tests or performance tests, which was often called performance assessments. The development model of the ANC assessment instrument used the procedure developed by the Oriondo and Dallo-Antonio [17] with modification, which consisted of 3 steps, including; 1) a preliminary study, 2) test design, 3) assessment.

\subsection{Development Procedure}

The first stage after went through a theoretical study, reviewing the Midwifery Diploma Education curriculum, preliminary observations about the continuous ANC competence assessment instrument in Midwifery Diploma Education, the initial draft was prepared. The initial draft contained the formulation of competency standards, fundamental competencies with indicators that had been compiled complete with grids and items discussed with experts, lecturers of ANC courses and midwife practitioners. In the initial stages, it produced a perfect grid and grains that are compatible with the ANC competence assessment instrument.

The Second Stage was more focused on efforts to develop instruments based on the grid of each basic competence and the indicators forming the ANC competency assessment. The third stage was validating and revising items as well as other inputs from experts. The involved experts were measurement experts, health curriculum experts, assessment and measurement experts, ANC course lecturers and midwife practitioners.

\subsection{Data Collection Instrument and Technique}

Data collection techniques and instruments largely determined the results of the data obtained. Data collection technique in the development of this instrument was observation. The selection of observation techniques with consideration was very useful in measuring performance assessment. The observation technique was equipped with a checklist-shaped observation sheet with alternative answers if done and shown in the tested performance given a checkmark $(\sqrt{ })$ and gave a score of 1 , but if it was not then left it and gave a score of 0 .

\subsection{Data Analysis Technique}

The data analysis technique in this research was to determine the validity of the contents of the instruments developed. The validity of the ANC competence assessment instrument was developed using a content validity test with the Aiken formula [18]. The purpose of the content validity test was to get an agreement by an expert on ANC competence, which had nine measured skills because the assessment made was intended to measure ANC competence. To find out the agreement of the expert, then item validity index was used as proposed by Aiken $[18,19]$. Aiken validity index was formulated as follows:

$$
V=\sum \mathrm{s} /(\mathrm{n}(\mathrm{c}-1))
$$

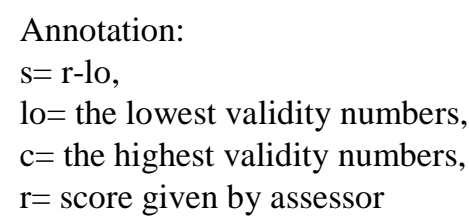

The amount of the $V$ value moved from $0-1$, the higher the $\mathrm{V}$ value, the more valid the instrument was made. According to Retnawati [20] Aikens agreement index results could be categorized into 3 categories, which were low validity $(<0,4)$, medium validity $(0,4-0,8)$ and high validity $(>0,8)$.

\section{Result and Discussion}

\subsection{Preliminary Study and Test Design}

"Formulated the constructs and indicators used in the ANC competency assessment instrument"

The first step of instrument development is by conducting preliminary study towards Head of Department, Head of Study Program, lecturers and students to get data related to competency assessment applied in Midwifery Diploma education. After learning that in midwifery education assessment instruments are still very simple, they are used to assess the skills of ANC procedures and clinical assessments equally. ANC competency assessment is not comprehensive because only aspects of the action procedure are assessed.

The next step is to conduct a workshop of curriculum review to find out construct that form ANC competency. The workshop results in ANC skill that must be mastered by students of Midwifery Diploma that are: communication, anamnesis, examination, medical team cooperation, handling decision making, conversation/ counselling, attitude, creativity and documentation.

After skills that must be mastered by students are determined, it is continued by a draft arrangement of a learning continuum model of ANC competency achievement in Midwifery Diploma Education, that involves experts. After the draft is arranged, it is continued by experts validation with the Delphi method and discussion with experts. Experts who conduct validation are involving four academic experts, five practitioners midwife of S2 graduate, and 6 ANC lecturers. The result of validation is a revision by adding several new CS 
(Competency Standards), BC (Basic Competency) and indicators after dividing $1 \mathrm{BC}$ into 2 or $3 \mathrm{BC}$ along with its indicators.

The next step is the arrangement of ANC competency assessment instrument development model: formulating purpose, competency determination, material determination and grid arrangement. The purpose of finding out ANC competency achieved by students of Midwifery Diploma in 4th, 5th and 6th semester. Competencies to be tested are ANC competencies in Midwifery Diploma students with 9 competency standards (CS), 19 basic competencies (BC) and 116 corresponding indicators.

After the grid is arranged, it is continued by a systematic compilation of competency material. The ANC competency material is systematically arranged as follows: communication, anamnesis, examination, teamwork, decision making, conversation/counselling, attitude, creativity and documentation.

The next step is to arrange the instrument items. ANC instruments developed in the form of checklists with a scale of $0-1$, with observation assessment technique so that the ANC instrument use observation guidelines. The arrangement of observation guideline items is based on the study of curriculum, policy, facility, feasibility, and practicality. The arrangement of observation guidelines items is based on a material grid with 9 CS and 19 BC. The instrument of ANC is arranged into observation sheets, with CS, BC orderly, and each indicator is compatible with BC. The observation sheet is arranged into instrument draft of ANC competency assessment.

\subsection{Assessment of Content Validity}

"To know content validity of the ANC competency assessment instrument"

The instrument items that have been arranged then continued by conducting content validity with Aiken approach. The total experts who conduct content validity are 21 experts that are 15 experts from ANC lecturer of Poltekkes Surakarta and Yogyakarta, and six experts came from midwives practitioners. The result of assessment towards instrument in the form of number 1-4 and next being analysed using Aiken formula. The result of content validity calculation can be seen in Table 1 .

Table 1. Result of Aiken validity calculation

\begin{tabular}{|c|c|c|}
\hline Validity & $\begin{array}{c}\text { Aiken Index } \\
\text { Average }\end{array}$ & Description \\
\hline $\begin{array}{c}\text { ANC Assessment } \\
\text { Instrument }\end{array}$ & 0.830 & $\begin{array}{c}\text { Extremely Valid } \\
\text { (high) }\end{array}$ \\
\hline
\end{tabular}

Table 2 is content validity calculation table use Aiken formula. The mean index obtained in the ANC assessment instrument is 0.830 . As for the agreement index if $<0.4$ then the validity is low, if between $0.4-0.8$ the validity is moderate (mediocre), and if $>0.8$ the validity is considered as high [20]. The average Aiken index obtained in this research instrument is considered as very valid (high validity). The validity of the contents of this instrument is appropriate for the ANC competency assessment data collection. Hasil lebih terperinci terlihat pada Table 2 dibawah ini.

Table 2. Result of Aiken validity calculation for Item

\begin{tabular}{|c|c|c|}
\hline Categories & N & No Item \\
\hline low validity $(<0,4)$ & - & Tidak ada item pada low validity \\
\hline $\begin{array}{c}\text { medium validity } \\
(0,4-0,8)\end{array}$ & 16 & $\begin{array}{c}\text { Item } 25,12,15,18,36,46,56,66, \\
76,81,85,86,91,95,96,115\end{array}$ \\
\hline high validity $(>0,8)$ & 100 & $\begin{array}{c}\text { Item-item yang tidak masuk ke } \\
\text { dalam category medium/low } \\
\text { validity }\end{array}$ \\
\hline
\end{tabular}

Indicators developed based on the results of content validation are then categorized based on BC and CS as appropriate in grid form. Competencies to be tested are ANC Competencies in Midwifery Diploma students with 9 competency standards (CS), 19 basic Competencies (BC) and 116 corresponding indicators. However, after the validation of the contents, there is a change in the instrument. After validation, Grid contains 9 CS, 18 BC and 116 indicators, the result indicates there is a difference in the number of basic competencies (BC). That's because some items are merged. In detail, CS, BC and instrument indicators can be examined in Table 3 below. 
Table 3. Instrument Grid

\begin{tabular}{|c|c|c|c|c|}
\hline No. & SK & KD & Indicator & No item \\
\hline 1. & Communication & $\begin{array}{c}\text { Communication main skill } \\
\text { Communication supporting skill }\end{array}$ & $\begin{array}{l}\text { Indicator 1-5. } \\
\text { Indicator 1-7. }\end{array}$ & $\begin{array}{l}1-5 \\
1-7\end{array}$ \\
\hline 2. & Anamnese & $\begin{array}{c}\text { Anamnese compulsory skill } \\
\text { Complementary skill }\end{array}$ & $\begin{array}{l}\text { Indicator 1-12 } \\
\text { Indicator 1-13. }\end{array}$ & $\begin{array}{l}1-12 \\
1-13 \\
\end{array}$ \\
\hline 3. & Examination & $\begin{array}{l}\text { Physical examination of compulsory skill. } \\
\text { Physical examination complementary skill. } \\
\text { Simple laboratory examination skill. }\end{array}$ & $\begin{array}{c}\text { Indicator 1-13. } \\
\text { Indicator 1-13. } \\
\text { Indicator 1-8. }\end{array}$ & $\begin{array}{c}1-13 \\
1-13 \\
1-8 \\
\end{array}$ \\
\hline 4. & Teamwork & $\begin{array}{l}\text { Main skill of taking a decision. } \\
\text { Supporting skill of taking the decision. }\end{array}$ & $\begin{array}{l}\text { Indicator 1-3. } \\
\text { Indicator 1-3. }\end{array}$ & $\begin{array}{l}1-3 \\
1-3\end{array}$ \\
\hline 5. & Taking decision & $\begin{array}{l}\text { The main skill of taking a decision. } \\
\text { Supporting skill of taking a decision. }\end{array}$ & $\begin{array}{l}\text { Indicator 1-3. } \\
\text { Indicator 1-2. }\end{array}$ & $\begin{array}{l}1-3 \\
1-2 \\
\end{array}$ \\
\hline 6. & Counselling & $\begin{array}{c}\text { Counselling main skill. } \\
\text { Counselling is a supporting skill. }\end{array}$ & $\begin{array}{l}\text { Indicator 1-6. } \\
\text { Indicator 1-5. }\end{array}$ & $\begin{array}{l}1-6 \\
1-5\end{array}$ \\
\hline 7. & Attitude/Affective & $\begin{array}{c}\text { Attitude main skill. } \\
\text { Attitude supporting skill. }\end{array}$ & $\begin{array}{l}\text { Indicator 1-5. } \\
\text { Indicator 1-4. }\end{array}$ & $\begin{array}{l}1-5 \\
1-4\end{array}$ \\
\hline 8. & Creativity & Creativity skill. & Indicator 1-7. & $1-4$ \\
\hline 9. & Documentation & $\begin{array}{c}\text { Documentation main skill. } \\
\text { Documentation supporting skill. }\end{array}$ & $\begin{array}{l}\text { Indicator 1-7. } \\
\text { Indicator 1-3. }\end{array}$ & $\begin{array}{l}1-7 \\
1-3\end{array}$ \\
\hline
\end{tabular}

\section{Conclusions}

The construct of the ANC competency assessment instrument for continuous education in the Midwifery Diploma consists of 18 constructs in the form of essential competencies (KD), that are: 1) main skill of communication; 2) communication support skill; 3) anamnese required skill; 4) anamnese support skill; 5) physical examination required skill; 6) complementary physical examination skills, and 7) simple lab examinations; 8) the main skills of cooperation; 9) cooperative support skills; 10) main skills to make decisions; 11) supporting skills to make decisions; 12) main conversation/counselling skills; 13) speech/counselling support skills; 14) main attitude skills; 15) attitude support skills; 16) creativity; 17) main documentation skills, and; 18) documentation support skills. The indicator used in the instrument of ANC competency assessment continuous education in Diploma Midwifery with 116 indicators. Based on the content validity using the Aiken formula, the Aikens index is 0.830 , meaning that the instrument content is declared very valid and can be used to measure ANC competency.

For lecturer of Midwifery Diploma Education, instrument of ANC competency assessment developed can be used to assess ANC competency of student of midwifery diploma, also to evaluate the achievement of ANC competency every semester. For Indonesian midwife organisations (Indonesian Midwife's Association/IBI), this can be used for conducting competency test for registration as new midwife or re-registration to extend the midwife license to practice. However, it is better than if the result of this research is followed by further in-depth research related to instrument developed by conducting field testing.

\section{REFERENCES}

[1] Hager, P., and Gonczi, A.: 'What is competence?', Medical teacher, 1996, 18, (1), pp. 15-18

[2] Epstein, R.M., and Hundert, E.M.: 'Defining and assessing professional competence’, Jama, 2002, 287, (2), pp. 226-235

[3] Fullerton, J.T., Ghérissi, A., Johnson, P.G., and Thompson, J.B.: 'Competence and competency: core concepts for international midwifery practice’, International Journal of Childbirth, 2011, 1, (1), pp. 4

[4] Kesehatan, P.M.: 'tentang Pelayanan Kesehatan Masa Sebelum Hamil', Masa Hamil, Persalinan, dan Masa Sesudah Melahirkan, Penyelenggaraan Pelayanan Kontrasepsi, serta Pelayanan Kesehatan Seksual, 2014

[5] Redfern, S., Norman, I., Calman, L., Watson, R., and Murrells, T.: 'Assessing competence to practise in nursing: a review of the literature', Research Papers in Education, 2002, 17, (1), pp. 51-77

[6] Smith, J.: 'Assessing and grading students' clinical practice: midwives' lived experience', Evidence-Based Midwifery, 2007, 5, (4), pp. 112-119

[7] Hindley, C.: 'An assessment of clinical competency on an undergraduate midwifery programme: midwives' and students' experiences', Journal of Clinical Excellence, 1999, 1, pp. $157-162$

[8] Wass, V., van der Vleuten, C., Shatzer, J., and Jones, R.: 'Medical education quartet', Assessment of clinical competence, 2001, 357, pp. 945-949

[9] Worth-Butler, M.M., Fraser, D.M., and Murphy, R.J.: 'Eliciting the views of experienced midwives about the assessment of competence in midwifery', Midwifery, 1996, 12, (4), pp. 182-190

[10] Norman, I.J., Watson, R., Murrells, T., Calman, L., and Redfern, S.: 'The validity and reliability of methods to assess the competence to practise of pre-registration nursing 
and midwifery students', International Journal of Nursing Studies, 2002, 39, (2), pp. 133-145

[11] Somers-Smith, M., and Race, A.J.: 'Assessment ofclinical skills in midwifery: some ethical and practical problems', Nurse Education Today, 1997, 17, (6), pp. 449-453

[12] Maxted, M., Grant, J., Wooding, K., and Norcini, J.: 'Assessing healthcare students in practice placements: an overview of the literature', Association for the Study of Medical Education (ASME), Edinburgh, 2004

[13] Robb, Y., and Dietert, C.: 'Measurement of clinical performance of nurses: a literature review', Nurse Education Today, 2002, 22, (4), pp. 293-300

[14] Denton, D.A.: 'National Health and Medical Research Council (NHMRC) 2009’, 2009

[15] Council, A.: 'Clinical practice guidelines: antenatal caremodule 1', Canberra: Australian Government Department of Health and Ageing, 2012

[16] KEMENKES, R.: 'Pedoman pelayanan antenatal terpadu', Direktur Jenderal Bina Kesehatan Masyarakat Kementerian Kesehatan Republik Indonesia, Jakarta, 2010

[17] Oriondo, L.L., and Dallo-Antonio, E.M.: 'Evaluating Educational Outcomes: Tests, Measurement and Evaluation' (Rex Book Store, 1984. 1984)

[18] Aiken, L.R.: 'Three coefficients for analyzing the reliability and validity of ratings', Educational and psychological measurement, 1985, 45, (1), pp. 131-142

[19] Ramadhan, S., Mardapi, D., Prasetyo, Z.K., and Utomo, H.B.: 'The Development of an Instrument to Measure the Higher Order Thinking Skill in Physics', European Journal of Educational Research, 2019, 8, (3), pp. 743-751

[20] Retnawati, H.: 'Validitas reliabilitas dan karakteristik butir', Yogyakarta: Parama Publishing, 2016 